\title{
Molecular and structural organization of lipids in foods: their fate during digestion and impact in nutrition
}

\author{
Anne Meynier* and Claude Genot \\ UR1268 BIA (Biopolymères Interactions Assemblages), INRA, 44316 Nantes, France
}

Received 16 January 2017 - Accepted 9 February 2017

\begin{abstract}
Lipids are basic constituents of our diet. They play an active part in the acceptability, flavour and perception of our foods. At the same time, they are also regarded as beneficial for health or as sources to various pathologies. Until now, the nutritional impact of the various dietary lipid structures beyond the amounts of ingested lipids and selected fatty acids has been marginally taken into account in nutritional studies and thus in food application. This review gathers first our current knowledge on the diversity of molecular and supramolecular structures of dietary lipids, and then based on the scientific studies carried out on the human model, tempts to sum up the current knowledge and the latest hypotheses concerning the metabolic and nutritional effects of these multiscale structures. It is shown that the perception of lipids in the mouth during oral processing modulates the production of digestive fluids and food intake. Then, during the stomach and intestine phases of lipid digestion, the kinetics of release of the fatty acids are modulated by the multiscale structures of lipids influencing the fatty acid bioaccessibility and rate of absorption. In turn this may impair the postabsorption metabolism and nutritional effects. Future trends of research are evoked as concluding remarks.
\end{abstract}

Keywords: dietary lipids / molecular and supramolecular structures / absorption / digestion / nutrition

\begin{abstract}
Résumé - Structures moléculaires et supramoléculaires des lipides dans les aliments : leur devenir au cours de la digestion et impact potentiel en nutrition. Les lipides prennent une part active dans l'acceptabilité et la perception de nos aliments, mais sont perçus à la fois comme vecteurs de tous les maux et sources de bienfaits. Au-delà de la quantité de lipides et d'acides gras ingérés, l'impact de leurs structures au sein des aliments reste encore mal appréhendé dans les études nutritionnelles. Cette revue, basée sur les travaux réalisés sur le modèle humain, fait le point des connaissances actuelles et des dernières hypothèses concernant les effets métaboliques et nutritionnels liés à la structuration aux échelles moléculaires et supramoléculaires des lipides alimentaires. Il apparaît que la perception des lipides commence dès la mise en bouche de l'aliment et module la prise alimentaire. Puis lors des phases stomacales et intestinales de la digestion, les nutriments lipidiques absorbables sont libérés des structures avec des cinétiques différentes, déterminant leur bioaccessibilité et influant leur vitesse d'absorption. Ces différences pourraient impacter le métabolisme post absorption et les effets nutritionnels. Des pistes de recherches possibles sont évoquées en perspectives.
\end{abstract}

Mots-clés : lipides alimentaires / structures moléculaires et supramoléculaires / absorption / digestion / nutrition

\section{Introduction}

Lipids are part of the human diet. They take an active part in the acceptability, flavor and perception of our foods. They supply energy and nutrients such as essential fatty acids (FAs), cholesterol and lipophilic vitamins. When consumed in appropriate amounts, they participate to overall well-being and health.

Latest available data from the French national study on individual food consumption (INCA2) underlined that the mean lipids consumption of the French adult population

\footnotetext{
* Correspondence: anne.meynier@inra.fr
}

represents 38\% of the EIEA $^{1}$ (Anses, 2015; Tressou et al., 2016); that is value in the range $(35-40 \%)$ of the last recommendations of the French agency (Anses, 2013). This average intake hides huge differences between consumers, the individual lipid intakes ranging from $50 \mathrm{~g}$ up to $150 \mathrm{~g} / \mathrm{day}$ (Armand, 2013). In fact, besides the total lipid intake, FAs are regarded as the elementary brick for nutrition: not only the quantitative lipids intake matters, but the qualitative aspect is also of importance with regard to health targets. Based on available data for food composition (Anses, 2013), the daily

\footnotetext{
${ }^{1}$ EIEA: energy intake excluding alcohol.
} 


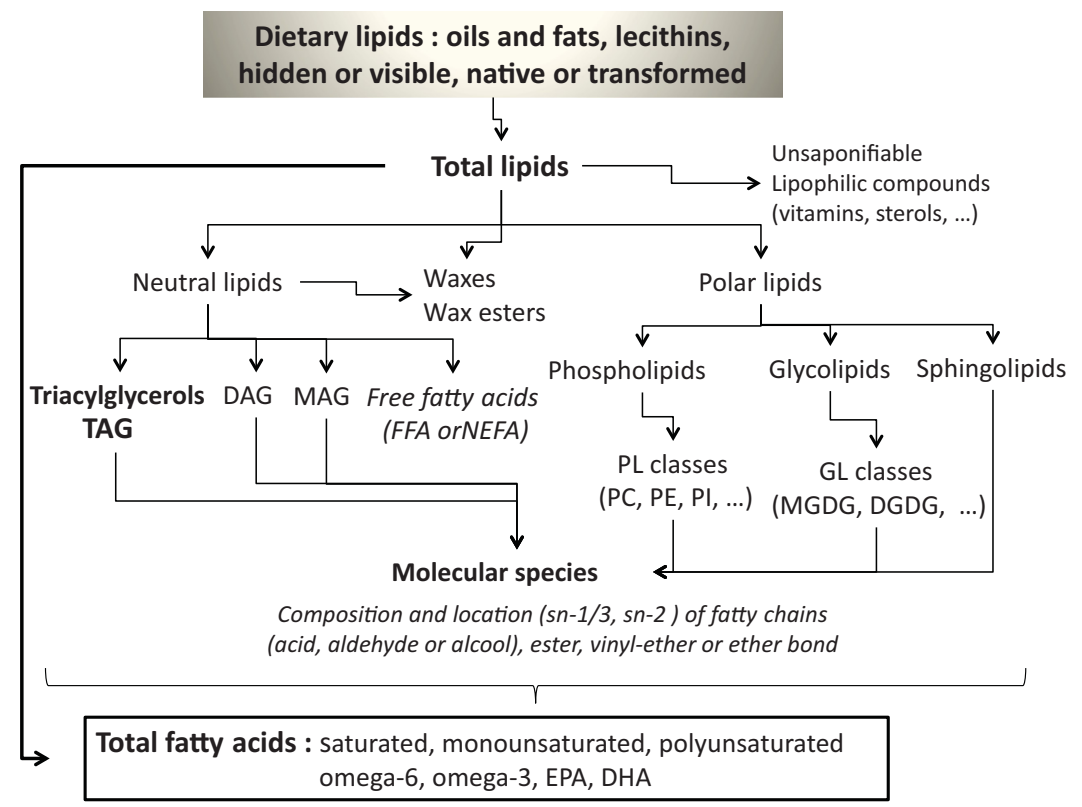

Fig. 1. Current classification of the main dietary lipids showing their molecular diversity.

intake were thus also converted into FA intakes which were compared to the up-to-date nutritional recommendations for each group of FAs (AFSSA, 2010). The conclusion is that the French population would rather: reduce its global intake of foods carrying saturated atherogenic lipids, namely lauric, myristic and palmitic acids; increase its intake of unsaturated lipids; and equilibrate its n-6 and n-3 FAs supply, the target being a n-6/n-3 ratio close to 5 , together with an higher intake in n-3 polyunsaturated FAs $\alpha$-linolenic acid, and long chain ones eicosapentaenoic (EPA) and docosahexaenoic acid (DHA) (Anses, 2015). Altogether, this would contribute to reduce the prevalence of metabolic and degenerative diseases and of cancers.

However, foods and more generally our diet do not provide FAs in the free form but as esters, mainly acylglycerols, merging various chemical and molecular structures organized into supramolecular edifices interacting with the other food constituents. The objective of this short review, mainly based on results from human studies, is to illustrate to what extend these structures may be used to better control the lipid fate after ingestion in order to optimize their nutritional and health benefits.

\section{The dietary lipids: their structural diversity beyond their fatty acids composition}

Dietary lipids originate from either crude or processed foods; they gather a wide range of chemical structures as presented in Figure 1. Triacylglycerols (TAGs) are by far the greatest source of dietary FAs accounting for up to $97 \%$ of the energy intake followed by polar lipids, mainly phospholipids (Armand, 2008). We postulate however that the intake of polar lipids could be underestimated because they are not fully characterized and quantified in some food sources due to analytical difficulties. Indeed, the proportions of lipid classes change from a food to another, as well as the lipid content and FA composition. Main acylglycerol classes contain different molecular species defined by the combination of the glycerol backbone (phosphorylated, glycosylated ...) esterified by various acyl groups. Esters bonds can sometimes be replaced by vinyl-ether or ether bond, leading to plasminogen and alkyl species derivatives. The external $(s n-1 / 3)$ or internal $(s n-2)$ distribution of the fatty chains on the glycerol backbone, which originates from the metabolism of the living food sources or can be modified by the processes, is another important parameter. The diversity of the dietary lipids (glycolipids, waxes and wax esters, alkyl lipids ...) tend also to increase with changes in food habits and possible introduction of new dietary sources and ingredients from new resources such as algae, microalgae, insects, fish rows for n-3 FA (Genot et al., 2016) and the tendency to consume less animal products and transformed foods. As detailed later on, due to specificities of the digestive enzymes, the digestive and metabolic fate of dietary FAs depends on these molecular structures.

Current nutritional information considers only the overall lipid content, the contents in selected FAs, such as saturated fatty acids (SFAs), polyunsaturated FA and sometimes the content in selected PUFA such as n-6 and n-3 PUFA. The great diversity of dietary lipids can be hardly considered in current nutritional recommendations, the message would be too complex to be understandable, but it is also generally not considered in nutritional studies. It is however important to keep in mind that the lipid content of a given food is not directly equivalent to the FA intake. As an example, Table 1 reports the FA contents of various lipids determined experimentally and reported in $\mathrm{mg} \mathrm{FA} / \mathrm{g}$ of analyzed lipids. Results for edible oils ranged from $900 \mathrm{mg}$ FA per $\mathrm{g}$ of sunflower oil down to $650 \mathrm{mg}$ FA per $\mathrm{g}$ of tuna oil. Similar pattern was observed for lecithins of various origins, where the fatty chain contents ranged from above $650 \mathrm{mg} / \mathrm{g}$ down to $370 \mathrm{mg} / \mathrm{g}$. The molecular composition of the glycerolipids (lysolipids, presence of a polar backbone) may explain some of the differences observed, but large differences may be 
Table 1. Amounts of fatty acids in several sources.

\begin{tabular}{ll}
\hline & Total fatty acids $(\mathrm{mg} / \mathrm{g})^{1}$ \\
\hline Triolein (calculation) & 945 \\
Sunflower oil & 900 \\
Oleic sunflower oil & 870 \\
Lard & 885 \\
Tuna oil & 650 \\
Soja lecithin & 664 \\
Egg lecithin & 600 \\
DHA-enriched lecithin & 370 \\
\hline
\end{tabular}

Data from Kabri et al. (2013) and ANR-08-ALIA-002 AGEcaninox. ${ }^{1}$ Quantification by gas chromatography of fatty acid methyl esters prepared by direct transmethylation of the fatty chains with $\mathrm{BF}_{3} /$ methanol in the presence of heptadecanoic acid as internal standard.

explained by the presence of unsaponifiable material made of compounds of great nutritional importance: sterols derivatives, lipophilic vitamin such as vitamin A, D or E. This should be taken into account for nutritional databases and when experimental balanced diets have to be formulated.
The supramolecular structure of lipids also differs from a food to another. Examples of native structures from animal or vegetal origins are presented in Figure 2. Complex supramolecular organizations are found for instance in egg yolk, milk fat globules or oilseed as oleosomes. Common characteristics are a TAG core surrounded by an interface or a membrane varying in composition, organization and complexity. In raw milk, the lipid globule is stabilized by a complex trilayer membrane made of phospho- and sphingo-lipids, cholesterol and proteins (Lopez, 2011; Raynal-Ljutovac et al., 2011). In egg yolk, the TAG core is stabilized by a monolayer interface containing phospholipids, proteins and cholesterol. In meat and muscle foods, phospholipids are mainly found as the typical bilayers of the cell membranes, while TAGs are gathered as droplets in the adipocytes of the adipose tissue. Formulated foods contain also particular lipid organizations. Water-in-oil and oil-in-water emulsions are the most representative structures, the oil droplets of the emulsions varying in size from the nano to the micrometric scale as well as in the nature of the stabilizing agents and the organization of the surrounding interface (solid particles, multilayer, ...). Some examples are presented in Figure 3 and have been reviewed more extensively (Meynier et al., 2013). Whatever the lipid

\section{B- Milk fat globules}

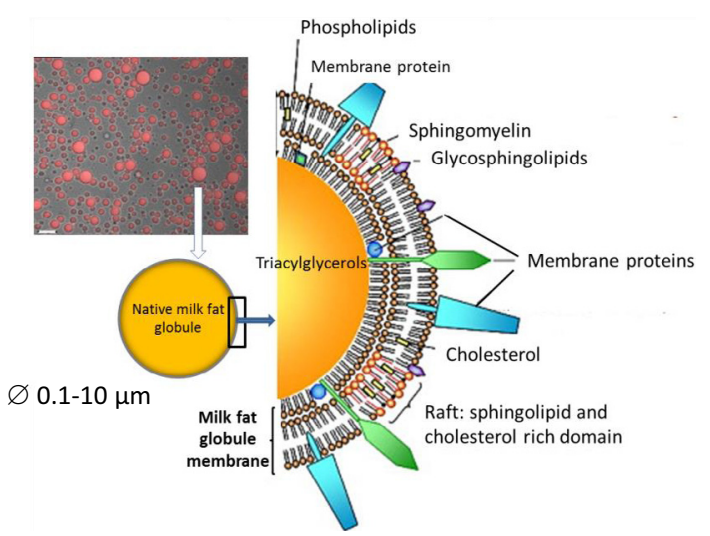

\section{A- Adipocytes and cell membranes in meat, fish and muscle foods}

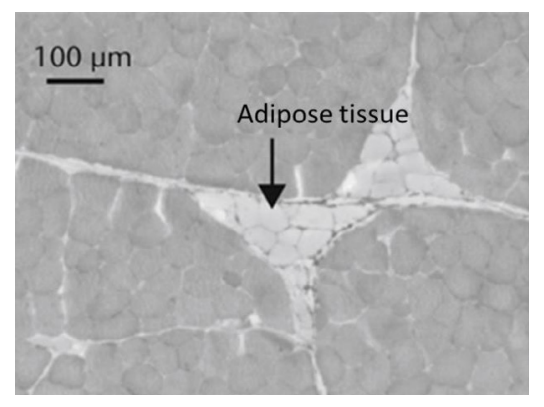

\section{E- Vegetable cells}
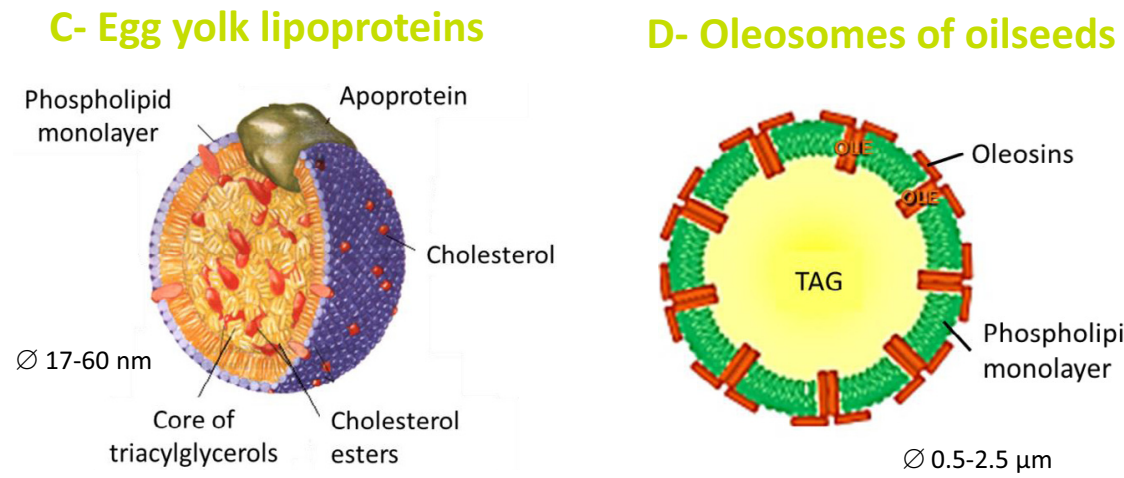

Low density lipoprotein

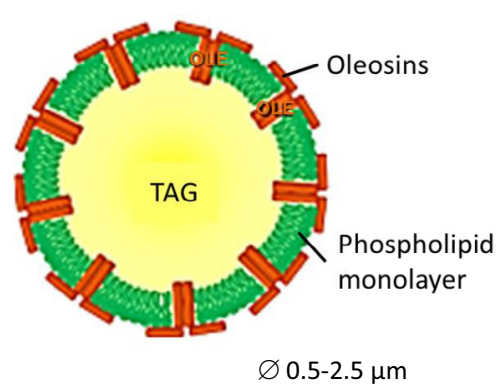

$\varnothing 0.5-2.5 \mu \mathrm{m}$

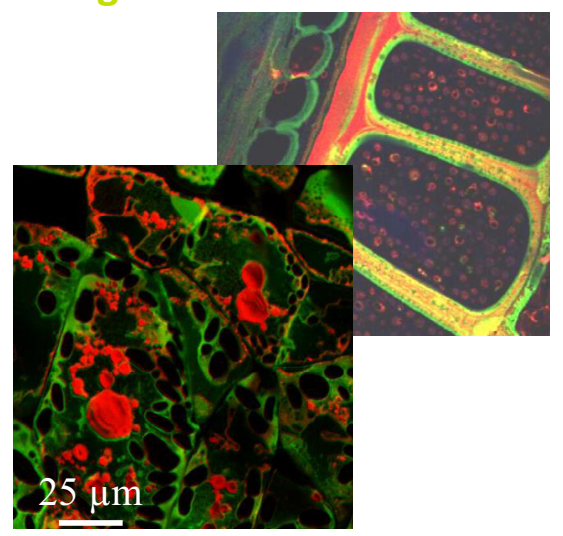

Fig. 2. Some examples of native structures of lipids in foods. Illustrations adapted from (A) Gondret F, Inra Phase, Saint Gilles; Raynal-Ljutovac et al. (2011); (B) Lopez et al. (2010); Raynal-Ljutovac et al. (2011); (C) Anton M, Inra BIA, Nantes; (D) D'Andrea (2016); (E) Plateforme BIBS/PVPP - Inra BIA, Nantes. 


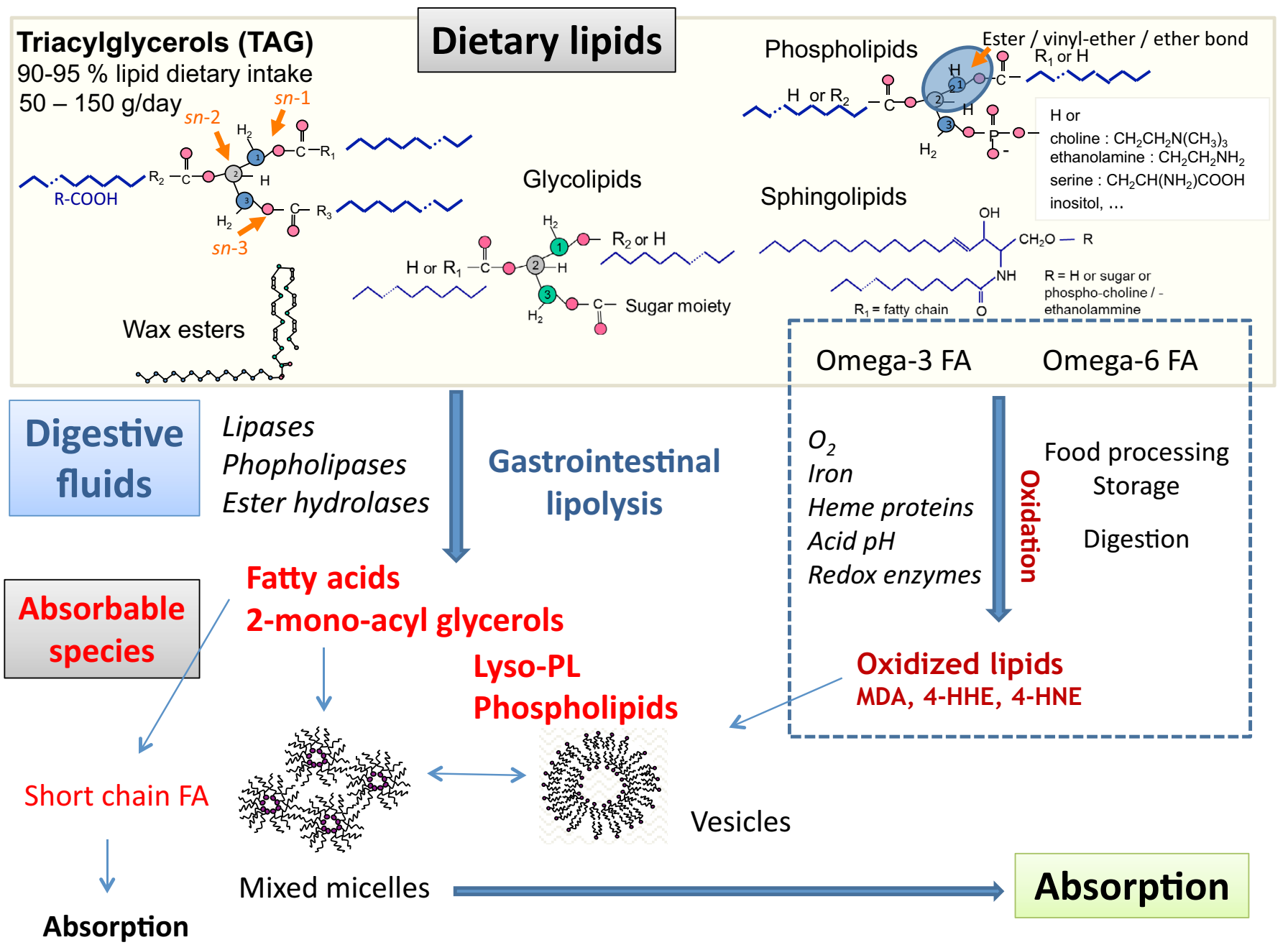

Fig. 3. The absorbable species formed during lipid digestion.

structures, they are also subject to changes from solid to liquid states depending on the temperature which can affect their accessibility to digestive enzymes.

In an overview, it should not be forgotten that dietary lipids are not only sources of energy and nutrients but are actively involved in properties such as texture, sensory properties and participate to the overall acceptability of foods. Both aspects must be considered when looking at a well-balance diet.

\section{Lipid structures affect the fate of dietary fatty acids in the GIT}

\subsection{Mouth}

In human, mastication and food oral processing can be considered as the first step of the digestion and prepare food to be swallowed and further transformed within the digestive tract (Feron and Salles, 2013).

It is now accepted that the oral perception of lipids stimulates their digestion and absorption. Free fatty acid (FFA) can be already present in the food product (generally less than $1 \%$ of total lipid intake). It has been also extrapolated from results obtained in the rat, that only a very low extent of lipolysis, arising from the hydrolytic activity of lingual lipase secreted by von Ebner gland, would be sufficient to release specifically FFA esterified in $s n-3$ of the glycerol backbone (Hamosh and Burns, 1977; Hamosh, 1990). The presence of a lingual lipase in human is however heavily debated as, so far, such a lipase has not been identified and characterized. After caption and transport by saliva, FFAs are detected by the neuro-sensory cells of taste buds through a specific receptor CD36 (cluster differentiation 36) (Laugerette et al., 2005; Besnard, 2016). In healthy adults, salivary lipolytic activity was correlated to the oral detection threshold of non-esterified oleic acid in emulsified lipids (Feron and Poette, 2013; Poette et al., 2014). These spate of events in the oral cavity have been postulated to increase the digestive secretions and optimize digestion and absorption of ingested lipids (Laugerette et al., 2005), as well as the mobilization of lipids stored in the enterocytes after previous meal (Mattes, 2011).

\subsection{Stomach}

In human, except for starch-containing foods, the digestion of food nutrients becomes really effective as the bolus reaches the stomach. TAGs are hydrolyzed by an acid lipase, the 
human gastric lipase (HGL). This enzyme is secreted by the chief cells of the fundic mucosa of the stomach (Moreau et al., 1988). It is active in a wide range of $\mathrm{pH}$ from 3.0 to 6.0 on short, medium and long chain TAGs with an optimum at $\mathrm{pH}$ 5.4 (Gargouri et al., 1986b); it hydrolyzes specifically the $s n-3$ ester bound, whatever the nature of the fatty chain, leading mainly to 1,2-diacylglycerols and FFA (Carrière et al., 1997). The gastric lipolysis is essential for (i) the formation of surface-active molecules such as FFAs and 1,2-DAGs that contribute to the gastric emulsification of dietary lipids (Armand et al., 1994) or play a part in the rearrangement of preexisting droplets; (ii) the release of FFAs that can be used for energy purpose, especially short and medium chain FAs $(\leq \mathrm{C} 12)$ that are absorbed by passive diffusion through the gastric mucosa (Hamosh et al., 1989; Lai and Ney, 1998); (iii) conditioning the subsequent activity of the pancreatic lipase (Gargouri et al., 1986a). In that way, the activity of gastric lipase stimulates the secretion of cholecystokinine (CCK) via the release of long-chain FAs, which in turn slows gastric emptying and activates pancreatic secretion (Hamosh, 1990) and shorten the latent phase between before the activation of the lipase-colipase complex depending on the nature of the released FFA (Borel et al., 1994). It was also estimated that HGL might also release $7.5 \%$ of the TAG acyl chains in the duodenum (Carrière et al., 1993). While it is limited in healthy adults (10 to $25 \%$ ), the contribution of gastric lipase could be quantitatively more important (30 to $60 \%$ of fat digestion) in specific physiological (preterm infants, new born) or pathological (cystic fibrosis, chronic pancreatitis) situations (Iverson et al., 1991; Armand et al., 1995, 1996b). This is rather due to a prolonged action of gastric lipase and low levels of pancreatic lipase, than to an increase in the intragastric lipolysis levels (Roman et al., 2007).

Lipid organization in meal can impair the extent of gastric lipolysis. In preterm infants, native human milk fat globules underwent a greater lipolysis that milk formula (1.7-2.5 fold), despite similar HGL output and activity (Armand et al., 1996b) which could be attributed to an effect on HGL activity of the different interface compositions and droplet size distributions. In healthy adults, isocaloric intake of liquid or solid meal led also to different gastric lipolysis, the solid meal being less hydrolyzed $(10 \%)$ than the finely emulsified liquid one $(25 \%)$ (Carrière et al., 2001).

Lipolysis is an interfacial reaction, the characteristics of the interface being decisive in the quantitative and qualitative course of the reaction. The interface surface area, which is directly related to the droplet size, its composition and organization, will modulate the lipolysis (Benzonana and Desnuelle, 1965). For instance, depending on the droplet size, the extent of gastric lipolysis in human adults ranged from 5 to 37\% (Armand et al., 1994, 1996a, 1999). With similar lipid intake, fine emulsions of $0.7 \mu \mathrm{m}$ underwent $35 \%$ gastric lipolysis, whereas larger ones of $10 \mu \mathrm{m}$ achieved $16 \%$ lipolysis (Armand et al., 1999).

The stability of the lipid droplets in the gastric environment should also be taken into account. Unstable droplets will tend to merge and separate from the aqueous phase, layering above the food bolus thus becoming inhomogeneous. As a consequence, the aqueous phase goes out from the stomach more rapidly than of the "layering" lipid phase. The lag time of oleic acid absorption was accordingly higher for subjects fed with "oil-on the top" meal $(75 \pm 10 \mathrm{~min})$ than for subjects fed "emulsified lipids" (37 $\pm 7 \mathrm{~min})$. Similarly, the time at maximum concentration was longer $(280 \pm 33 \mathrm{~min} v s .162 \pm 18 \mathrm{~min})$ and the release of CCK significantly increased after a second meal (Foltz et al., 2009). The choice of the surfactant is a key to control for the stability of an emulsion in the gastric environment. For example Tween 60 (E491, polyethoxy ethylene sorbitan monostearate) or Span 80 (E494, sorbitan monooleate) can be used to produce respectively acid-stable or unstable emulsions (Marciani et al., 2007) with similar droplet size $(3.6 \mu \mathrm{m})$. Those emulsions were incorporated into a complete meal ( $500 \mathrm{ml}, 675 \mathrm{kcal}, 50 \mathrm{~g}$ lipids) and $5 \mathrm{~h}$ after their ingestion, subjects ingested $500 \mathrm{ml}$ of a rehydrated vegetable soup ( $460 \mathrm{kcal}, 12.5 \mathrm{~g}$ fat). Fullness, appetite and hunger were assessed together with plasmatic CCK, gastric emptying and gallbladder volume by Magnetic Resonance Imaging. As previously mentioned, the acid-unstable emulsion was rapidly broken, leading to phase separation. The aqueous phase emptied more rapidly $(72 \pm 13 \mathrm{~min})$ than the overall stable emulsion $(171 \pm 35 \mathrm{~min})$. Furthermore, the shape of emptying curve was exponential for unstable meal instead of linear for stable emulsion. More CCK was released after ingestion of the acid stable meal $(1095 \pm 244$ pmole $\mathrm{min} / \mathrm{L})$ than after acid unstable meal $(531 \pm 111$ pmole $\mathrm{min} / \mathrm{L})$, inducing a greater gallbladder contraction and decreasing postprandial appetite (Marciani et al., 2007). In another study, authors confirmed that acid-stable meals quitted more rapidly the stomach than acid-unstable meals and once in the duodenum lipids would be hydrolyzed more rapidly because of the higher surface area available for lipase/colipase complex (Marciani et al., 2009). Authors expected also an impact on CCK release and on satiety. The gastric emptying was linear for all emulsions while the coarse unstable emulsion $(6 \mu \mathrm{m})$ emptied more rapidly $\left(t_{1 / 2} 180 \pm 9 \mathrm{~min}\right)$ than the fine and coarse stable ones $\left(t_{1 / 2}: 230\right.$ for $6 \mu \mathrm{m}, 330 \pm 61 \mathrm{~min}$ for $0.4 \mu \mathrm{m})$, without significant modification of the rate of energy delivery from the stomach into the duodenum up to $110 \mathrm{~min}(1.98 \pm 0.22 \mathrm{vs} .1 .67 \pm 0.48 \mathrm{kcal} / \mathrm{min})$. Additionally, no significant difference was highlighted in the plasmatic postprandial lipemia or on gallbladder contraction (Marciani et al., 2009). The stabilization of emulsion by Locust Bean Gum increased the AUC of plasmatic CCK, while this parameter was not significantly modified by droplet size changes. The lipid absorption was delayed after consumption of acid-stable emulsion compared to unstable one, droplet size exhibiting limited impact. Finally, the food intake after consumption of the emulsions was significantly reduced for acid-stable emulsion and further reduced by a decrease of the droplet size (Hussein et al., 2015).

\subsection{Intestine}

The median $\mathrm{pH}$ value of the duodenum in the fasted state was 6.2 and reported values ranged from 5.95 up to 6.72 (Kalantzi et al., 2006). In fed state, the pH of the duodenal contents stayed close to 6.0 during the first half of the gastric emptying. It then decreased slightly to $\mathrm{pH}$ values around 5.5 before returning to its basal values of 6.0-7.0 (Carrière et al., 1993). Contrarily to the stomach, several enzymes could hydrolyze lipids in the small intestine, and their characteristics have been reviewed (Armand, 2007; Bakala N'Goma et al., 2012). The human pancreatic lipase (HPL) was found to be responsible for 40 to $70 \%$ of the TAG lipolysis (Carrière et al., 
1993; Armand et al., 1996a, 1999). Other enzymes with lipid hydrolytic activities are also present in the intestine fluids, such as pancreatic lipase related protein 1 and 2 (PLRP1 and PLRP2), carboxyl ester lipase (CEL), which is the same enzyme as Bile salt-stimulated lipase (BSSL) important for new born and phospholipase A2 (Armand, 2013) their exact contribution to digestion of dietary lipid has been less investigated (Carrière, 2017, OCL, GLN 2016 conference). The HPL is synthetized by the acinar cell of the pancreas and secreted optimally to ensure efficient lipid digestion in healthy adults (Armand, 2007). Thus, an increase of the HPL secretion has been noticed after the consumption of a high fat diet (45-50 g lipids) compared to a low fat one (12.5 g) by healthy adults (Boivin et al., 1990). To absorb on the oil-water interface in presence of bile salts, the HPL requires the presence of co-lipase. The complex formed by the lipase and co-lipase hydrolyzes the ester bond in $s n-1$ and $s n-3$ positions of TAG. The type of FA impairs the rate of lipolysis: mediumchain FA or monounsaturated ones are hydrolyzed more rapidly than long chain ones, especially very-long chain polyunsaturated FAs (Mu and Porsgaard, 2005). The HPL output was maximum during the first hour after the ingestion of a liquid meal $(55 \pm 11 \mathrm{mg})$ and was found to decrease after $3 \mathrm{~h}$ (13.5 $\pm 7.5 \mathrm{mg}$ ) (Carrière et al., 1993). In a similar study, the total HPL output after the ingestion of a liquid or solid meal was found to be close to $250 \mathrm{mg}$ for the liquid meal and to $200 \mathrm{mg}$ for the solid meal (Carrière et al., 2000).

Depending on the droplet size, TAG hydrolysis ranged from 30 to $75 \%$ in the duodenum (Armand et al., 1994, 1996a, 1999). For equivalent lipid intake, small droplets (initial droplet size $0.7 \mu \mathrm{m}$ ) exhibited a lipolysis of $73 \% v s$. $46 \%$ for large initial droplet $(10 \mu \mathrm{m})$ (Armand et al., 1999). Authors claimed that in physiological condition, lipases are in excess relative to the substrate. This statement was qualified later by raising the question of the substrate used to determine the activity of the lipase (Carrière et al., 2005). Indeed, the specific activity of HPL can vary at $\mathrm{pH} 8.0$ from 8000 to $12,500 \mathrm{U} / \mathrm{mg}$ of proteins on tributyrin emulsions to $3000 \mathrm{U} / \mathrm{mg}$ on olive oil emulsions and even down to $15 \mathrm{U} / \mathrm{mg}$ at $\mathrm{pH} 6.25$ on solid-liquid meals. It is likely that the pancreas secretes enough lipases to digest dietary lipid in the postprandial period but contrary to what is commonly mentioned, the quantities secreted are not in large excess (Carrière et al., 2005). A larger lipid-water interface area, as obtained with smaller droplets, will allow the binding of more lipase molecule and consequently an increased lipolysis. Furthermore, the composition and organization of this lipid/water interface can modulate lipase/colipase absorption through surface load or interaction with particular compounds such as phospholipids (Favé et al., 2007). The formation of 2 mole of FFA and 1 mole of 2-MAG for one TAG is in theory sufficient for the complete absorption of dietary fat and TAG re-synthesis in the enterocyte. Nevertheless, MAG can be further hydrolyzed by enzymes having monoglyceride activity like CEL and PLRP2 (Armand, 2007; Bakala N'Goma et al., 2012). This could explain why part of the FAs at position sn-2 of TAG can be exchanged upon digestion, absorption and chylomicron (CM) synthesis (Couedelo et al., 2012). To be absorbed by the border brush membrane of the enterocytes, FFA and 2-MAG must be incorporated in nanoscale structures containing bile salts and called mixed micelles $(8-20 \mathrm{~nm})$ or into larger structures designed as vesicles $(40-200 \mathrm{~nm})$ containing phospholipids as well (Armand, 2013). The extent of FFA and MAG that can be solubilized into mixed micelles also seems depend on the molecule (Hofmann, 1963; Freeman, 1969). For instance, the molar saturation ratio (mole of incorporated products/mole of bile salts) in a sodium glycodeoxycholate solution at $37^{\circ} \mathrm{C}$ has been reported to vary from 0.07 for stearic acid to 1.86 for lauric acid with intermediate values for long chain unsaturated FFA such as oleic and linoleic acids (Freeman, 1969).

\subsection{After absorption}

Lipid absorption occurs either by passive diffusion through the enterocyte membrane (Hamilton, 2007) or through specific transport to the brush border membrane after binding to transporters such as FATP4 (fatty acid transport protein 4) or CD36 or SR-B1 (Scavenger receptor class B1 for cholesterol). Complex enzymatic systems re-synthetize TAG from 2-MAG and FFA, which are transported through lymph and different target organs by lipoproteins structures designed as chylomicrons (CMs) (Lo and Tso, 2009). The rate of appearance and extent of lipid present in the lymphatic system following fat ingestion (postprandial state) gives an indication of the bioavailability of the dietary lipids (Carey et al., 1983; Iqbal and Hussain, 2009).

Some data suggest that lipid absorption can be modulated by enhancing the gastrointestinal lipolysis via the emulsification of dietary lipids (Couedelo et al., 2015). Thus, some studies have evidenced the faster absorption and metabolization of emulsified lipids than unemulsified one (Garaiova et al., 2007; Vors et al., 2013). Additionally, the nature of the emulsifiers can affect the metabolism of lymph CM (Daher et al., 2003) and the concentration of TAG in plasma (Keogh et al., 2011). Indeed, the improvement of intestinal lipid absorption would enhance the accretion of TAG in CM in rat lymph (Masuda et al., 2009). The CMs structure can be affected to dietary fat and it turn can impair plasma lipemia (Couedelo et al., 2015). Small CM would be more atherogenic than larger ones related to the limiting rate of hydrolysis of CMs TAG by the lipoprotein lipase (LPL) (Mekki et al., 2002).

In a recent study coupling in vitro and in vivo approach, the emulsification of flaxseed oil, source of $\alpha$-linolenic acid, with soya lecithin enhanced the extent of in vitro lipolysis compared to bulk oil or emulsions stabilized by either sodium caseinate or Tween 80 . In vivo data demonstrated that intestinal absorption and lymphatic secretion of $\alpha$-linolenic acid were also improved after ingestion of the same phospholipid-stabilized emulsion vs. bulk flaxseed oil. Finally, the CM were larger and more numerous after ingestion of PL-stabilized emulsion compared to smaller one after ingestion of caseinate-stabilized emulsions (Couedelo et al., 2015). Authors also investigated the conversion of $\alpha$-linolenic acid to eicosaenoic (EPA) and DHAs in various tissues (lymph, liver, serum). Higher levels of $\alpha$-linolenic acid were present in rat lymph after feeding emulsions stabilized by whey protein $(+41 \%)$ or phospholipids $(+103 \%)$ compared to bulk oil. Little conversion of $\alpha$-linolenic acid was observed 
in the lymph lipids; nevertheless, significant amounts of EPA and DHA were observed in liver and serum after feeding rat for 60 days with the emulsified oils $(0.5 \%$ with bulk oil; $0.7 \%$ after ingestion of protein-stabilized emulsion and $1.5 \%$ after ingestion of phospholipid-stabilized emulsions). Conversely, the proportion of $n-6$ FA in the lymph lipids decreased significantly (Sugasini et al., 2014). Comparison of the results obtained on lymph and liver (Fig. 6) led the authors to conclude that $\alpha$-linolenic acid was converted into EPA and DHA in the liver. Consequently, the $n-6 / n-3$ of the various tissues was deeply depended on the intake form of lipids, phospholipid-stabilized emulsion being the most efficient to reduce n-6/n-3 (in liver $1.3 v s .7 .3$ for bulk oil). Similar trends were observed in serum (Sugasini et al., 2014). Altogether, these results indicate that appropriate formulation of lipid carrier can not only enhance the absorption and accretion of dedicated FA but also their conversion to long chain polyunsaturated FA.

Another promising approach was the design of particular lipid that will be able to address a specific FA such as DHA to a target organ such as brain (Lagarde et al., 2001; Lagarde and Bernoud-Hubac, 2012) as presented later (OCL + GLN, 2016; Bernoud-Hubac et al., 2017).

\section{Structuration of dietary lipids: a tool to targeted nutrition?}

The control of lipid bioavailability and lipid absorption is emergently questioned since the middle of the 2000s with a rapid boom of related scientific publications. The lipid bioavailability control addresses two opposite situations as regards of improvement of human health and well-being. In the first situation, the aim is to increase, promote or optimize the absorption and the use by the body of certain lipids, beneficial for health but under-consumed or of limited bioavailability. Typically, it concerns energy supply by SFAs or indispensable FA supply for preterm infant and new born or for subjects suffering of permanent or transitory digestive insufficiencies. The increase the long-chain omega-3 PUFA intake and absorption to cover the nutritional needs of general or targeted populations for health benefits is also included. The second situation is linked to the over-consumption of junky foods and its deleterious health consequences (overweight, metabolic syndrome, diabetes mellitus ...). The objective is either to reduce lipid absorption for overweighed, hyperlipidemics or metabolic syndrome subjects (Armand, 2013) or to reduce the fat and food intake by increasing the satiety. As recently reviewed, the structure of dietary lipids can affect FA bioavailability and lipid metabolism (Michalski et al., 2013). Many newly designed lipid structures and formulations paired with generally in vitro digestion trials has been accordingly performed in the objective to take advantage of the two levels of structures previously described, namely (i) the molecular level, gathering TAGs structured naturally or by the process to control the regiodistribution of FAs on the glycerol backbone and the various classes of lipids (Fig. 1) and (ii) the supramolecular level, including the colloidal organizations of lipid in foods, one of the main model being oil-in-water emulsions and their insertion in a complex food matrix.

\subsection{Molecular structure of dietary lipids}

\subsubsection{Structured lipids}

The knowledge and control of TAG structure in addition to their FA composition are of importance to understand nutritional effects of dietary fats and reach the health targets. TAG molecules making up adipose tissue of current livestock animals have predominantly a saturated FA in $s n-1$ position and an unsaturated FA at $s n-2$ position. Seed oils exhibit PUFA mostly esterified at $s n-2$ position. In vegetable oils, saturated FA occurs primarily at $s n-1$ position (Karupaiah and Sundram, 2007). The TAG structure of natural fats and oils and their nutritional properties can be modified either by use of lipases as catalysts or by chemical modifications (Linderborg and Kallio, 2005). An example of structured fat design for dedicated nutrition is Betapol, a vegetable lipid blend exhibiting similar TAG structure that the ones of human milk. This structure favors the absorption of palmitic acid, which is esterified in $s n-2$ position (as in human milk) and reduces its loss in feces. Fecal losses of saturated lipids are favored by the formation in the GIT of insoluble soaps between calcium or other divalent ions and the SFAs esterified in $s n-1$ or $s n-3$ positions of fats, preferentially and rapidly released by the digestive enzymes (Linderborg and Kallio, 2005; Mu and Porsgaard, 2005; Karupaiah and Sundram, 2007). This effect is favored because an increased concentration of bile salts is needed to maintain SFAs with melting point above the body temperature in mixed micelles (Linderborg and Kallio, 2005). Once in the blood stream, saturated FA in the $s n-2$ position delay the clearance of CM and lipoproteins remnants, probably due to alteration in the physical properties of CM interface that impair the activity of the LPL (Linderborg and Kallio, 2005).

Fish oils and marine mammal fats exhibit different locations of their long chain PUFA in the TAG structures. EPA and DHA are mainly esterified in $s n-2$ position in fish oils instead of $s n-1$ or $s n-3$ position in mammal oils. After intragastric administration of fish or seal oil to rats, the lymphatic transport was found to be higher during the first $8 \mathrm{~h}$ with fish oil (Christensen et al., 1994). Twenty hours after the intake, there was no difference in the accumulated transport of FAs, but the resultant $\mathrm{CM}$ reflected the dietary TAG in regard to the location of LC n-3 PUFA (Christensen and Hoy, 1996), in agreement with other works (Yoshida et al., 1999).

Another potential application of structured lipids (TAG) is the design of particular species containing medium chain FA in $s n-1$ and $s n-3$ position and PUFA in $s n-2$ position, allowing the rapid hydrolysis of MCFA and their use for energy purpose, and the efficient absorption of PUFA, typically arachidonic, EPA or DHA. This characteristic is of importance for patients suffering from fat malabsorption (Linderborg and Kallio, 2005; Mu and Porsgaard, 2005; Michalski et al., 2013).

\subsubsection{TAG vs. PL, others}

Always at the molecular level, FA can be carried either by TAG or by phospholipids. This can be of particular interest when looking at source of LC-PUFA and especially EPA and DHA. Results and tendencies can differ in animal or human studies, and according to the outcome e.g. infant, healthy adult, hyperlipidemic subject (Michalski et al., 2013). Nonetheless, 


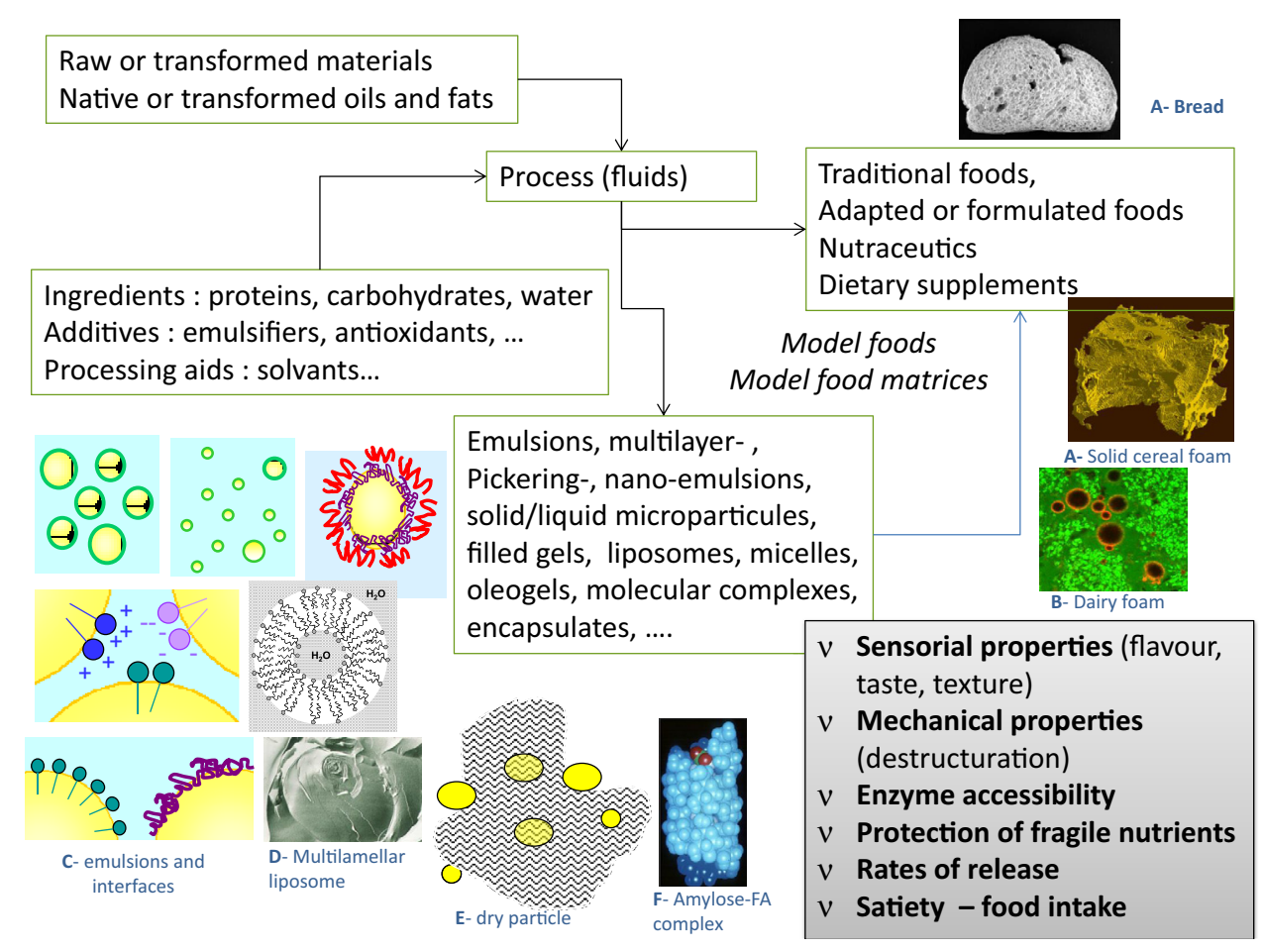

Fig. 4. Schematic representation of designed formulated supramolecular structures of lipids that can be formed during food processing and their possible impact on ingestion, digestion and metabolism of lipids. Illustrations adapted from (A) Della Valle G, Guessasma S, Inra BIA Nantes; (B) Bréard CInra BIA Nantes; (C) Genot et al. (2013a); (D) Genot et al. (1989); (E) Genot et al. (2004); (F) Le Bail P. Inra BIA Nantes.

at equivalent quantities of PUFA, PL seemed to be more efficient to impair the adverse effect of high fat diet than TAG (Awada et al., 2013; Genot et al., 2016). Krill oil (containing PL) was more effective than fish oil when consumed during 3 months to reduce glucose, TAG and LDL levels in hypercholesterolemic patients (Bunea et al., 2004).

The question of the sustainability of nutrients sources led to the diversification of the resources. Recently, wax ester oil from a marine crustacean was found to be a source of bioavailable EPA and DHA in human (Cook et al., 2016).

\subsection{Supramolecular structure of dietary lipids}

Dietary lipids are either visible or hidden. Visible fats are non-emulsified lipids such as oils, adipose tissues or water-inoil emulsions such as butter and spreads. Hidden fats are dispersed in the form of droplets, with size ranging from of several ten nm to few hundreds $\mu \mathrm{m}$, surrounded by a liquid or semi-liquid, aqueous phase (oil-in-water emulsions) or inserted in a solid phase (encapsulated lipids). In oil-in-water emulsions, the TAG phase is stabilized by surface-active molecules, namely polar lipids, surfactants or proteins, socalled food-grade emulsifiers (Michalski et al., 2013). In raw foods, dietary PL and more generally polar lipids are also present in cell membranes (e.g. meat, fish) or at the TAG/water interface of natural assemblies such as oleosomes, lipoproteins of egg yolk and milk fat globules. These natural organizations are shown in Figure 2. In processed foods, lecithins of vegetable origin (e.g. soya, rapeseed, sunflower) or animal origin (e.g. egg yolk) and MAG and DAG, possibly after additional treatments (fractionation, hydrolysis, hydrogena- tion), are widely used in the food industry as stabilizing agents and as emulsifiers. Lecithins from brain, krill or MFGM are other potential sources of lecithins (Michalski et al., 2013). Indeed, the composition in FA and polar lipid classes of these lecithins varies in large proportions according to their origin and the production process. These polar lipids adsorb at the surface of the TAG droplets, making them less sensitive to destabilization phenomena (Genot et al., 2013a). They are also able to interact with the components of the food matrix such as proteins and polysaccharides (i.e. starch).

The dispersion of lipids in the form of droplets, their size and interfacial composition may affect the kinetics of lipid digestion and absorption as previously reviewed (Favé et al., 2004; Armand, 2007; Singh et al., 2009). Since then, the interest of emulsion as carrier or delivery systems for nutrients, lipophilic bioactive compounds or drugs is booming (Velikov and Pelan, 2008; Raynal-Ljutovac et al., 2011; Yao et al., 2014; Livney, 2015; Mao and Miao, 2015; Norton et al., 2015; Singh et al., 2015; Joyce et al., 2016; Zhang et al., 2016). Some schematic structures of these delivery structures are presented in Figure 3. Incorporation of nutrients such as lipids or bioactive compounds such as vitamins or antioxidants in emulsion is claimed to provide a simple way to develop novel functional foods with desirable health benefits and suitable sensory properties (Mao and Miao, 2015). Whatever the design, the delivery emulsions need to be palatable, stable and easy to process or incorporate in dedicated foods. Last, but not least, the structuration of water continuous phase, dispersed oily phase and interface can be a tool to control the release of the component at the dedicated place (mouth, stomach, intestine, tissue) (Fig. 4). 


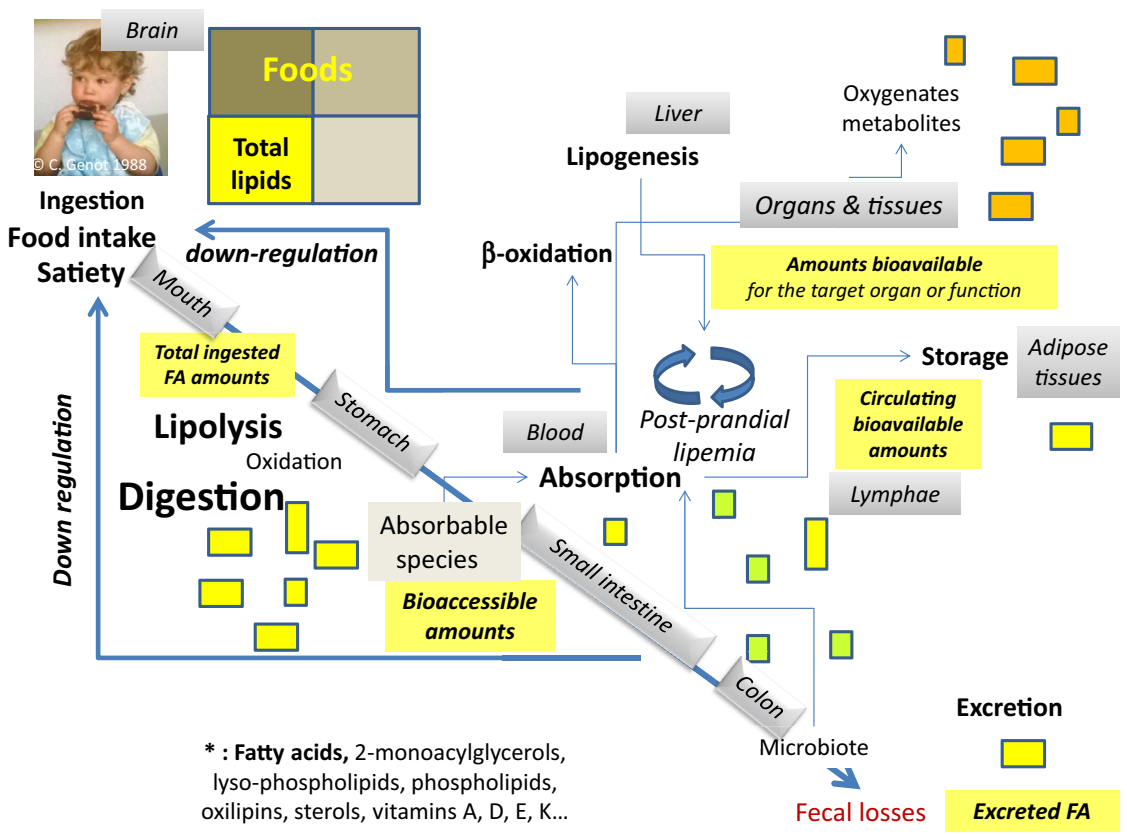

Fig. 5. Schematic overview of lipid digestion, metabolism highlighting crucial steps and some regulation pathways.
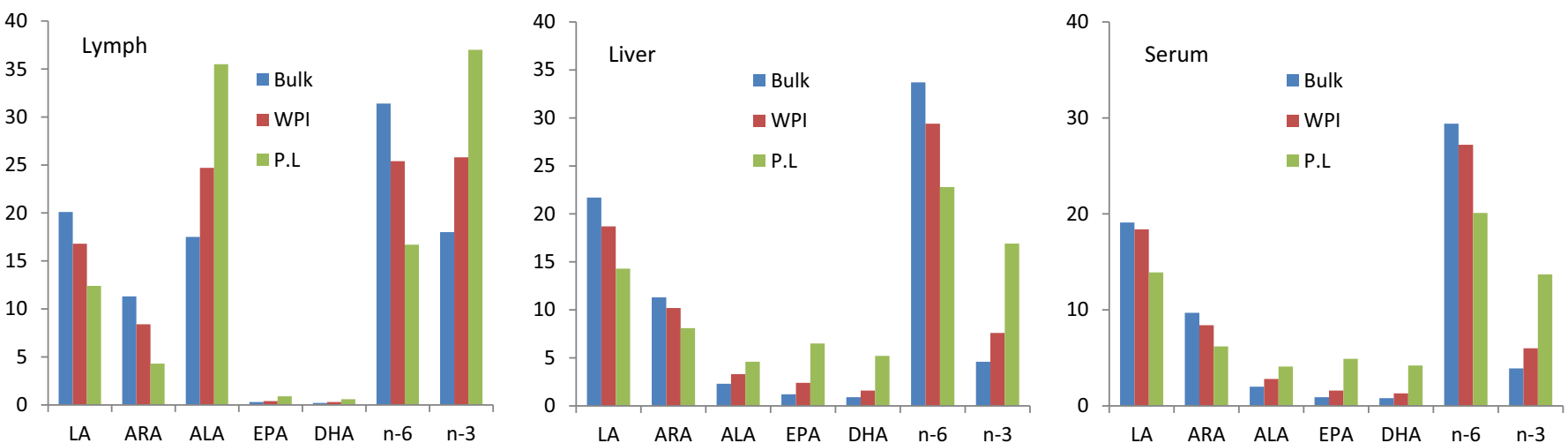

Fig. 6. Evolution of the fatty acid composition of lipids of various tissues after 60 days feeding with bulk linseed oil (Bulk), whey proteinstabilized emulsion (WPI) and phospholipid-stabilized emulsion (P.L) of the same linseed oil. Adapted from Sugasini et al. (2014).

We have already mentioned that the interface composition influences lipase absorption and lipid digestibility. Two main mechanisms were involved: (i) alteration of the colloidal stability of the lipid droplets in the stomach and intestine impacts the rate and extent of droplet coalescence or destabilization, (ii) alteration of gastric and pancreatic lipase affinity for the substrate and thereby, the rate of enzyme adsorption to the lipid surface (Joyce et al., 2016).

Double emulsions have found great application in the encapsulation of hydrophilic and hydrophobic compounds, respectively, in the internal and external droplets or encapsulation of compounds with unpleasant taste or flavor. These systems have potential use as salt or fat reduction technologies for liquid and semi-solid food without altering their sensory properties (Norton et al., 2015). Pickering particles strongly adsorb at the interface and provide enhanced stability. Examples are fat crystals or starches and egg-yolk particles (Marefati et al., 2013; Rayner et al., 2014; Norton et al., 2015). These structures could have some applications in flavor encapsulation or protection against oxidation (Kargar et al., 2011).

Those works on the emulsion and delivery design could have potential applications to increase the bioavailability and absorption of PUFAs or conversely to control food intake or limit lipid absorption in the context of increased prevalence of obesity and metabolic diseases related to diet (McClements, 2015; Corstens et al., 2017).

\section{Concluding remarks}

To sum up our purpose, a schematic overview of the digestion and metabolism of dietary lipids is proposed in Figure 5. This scheme allows an easy visualization of the levels where the molecular and/or supramolecular structures of lipids can be a way for controlling lipid metabolism. To summarize, they can affect (i) fat perception, food intake and satiety, (ii) the rates and location of release of absorbable species in the GIT 
and thus absorption kinetics and following cascades of metabolic events and (iii) organ/function targeting. Up, to now, many avenues and applications have been imagined or set up to apply these concepts, but few demonstrative in vivo studies have been published. We think that the successful application of lipid structure design to foods and nutrition will require gathering a broad range of knowledge and skills including analytics, physico-chemistry, processing and metabolism of oils, fats and foods; taking into account properties and interactions of food constituents, biology and metabolism function of targeted nutrients or bioactive compounds. These scientific domains cannot be considered independently and require integrated approaches (Velikov and Pelan, 2008). Besides bioavailability and metabolic effect, all aspects of product functionality such as stability, taste, texture, appearance but also technical feasibility and price and environmental outputs should be also considered and addressed to obtain balanced and consumer acceptable products.

Conflict of interest. The authors declare that they have no conflicts of interest in relation to this article.

\section{References}

AFSSA. 2010. Avis de l'agence française de sécurité sanitaire des aliments relatif à l'actualisation des apports nutritionnels conseillés pour les acides gras. http://www.anses.fr/Documents/ NUT2006sa0359.pdf.

Anses. 2013. Table de composition nutritionnelle des aliments. Ciqual, 2013. https://pro.anses.fr/tableciqual/.

Anses. 2015. Apports en acides gras de la population vivant en france et comparaison aux apports nutritionnels conseillés définis en 2010. Avis de l'anses. Rapport d'étude, 244 p.

Armand M. 2007. Lipases and lipolysis in the human digestive tract: Where do we stand? Curr Opin Clin Nutr Metabol Care 10: 156164.

Armand M. 2008. Digestibilité des matières grasses chez l'homme. Sci Alim 28: 84-98.

Armand M. 2013. Stratégies de contrôle de la biodisponibilité des lipides. In: Fardet A, Souchon I, Dupont D, eds. Structure des aliments et effets nutritionnels. Paris: QUAE, pp. 373-413.

Armand M, Borel P, Dubois C, et al. 1994. Characterization of emulsions and lipolysis of dietary lipids in the human stomach. Am J Physiol Gastrointest Liver Physiol 266: G372-G381.

Armand M, Hamosh M, Dipalma JS, et al. 1995. Dietary-fat modulates gastric lipase activity in healthy humans. Am J Clin Nutr 62: 74-80.

Armand M, Borel P, Pasquier B, et al. 1996a. Physicochemical characteristics of emulsions during fat digestion in human, stomach and duodenum. Am J Physiol Gastrointest Liver Physiol 271: G172-G183.

Armand M, Hamosh M, Mehta NR, et al. 1996b. Effect of human milk or formula on gastric function and fat digestion in the premature infant. Pediatr Res 40: 429-437.

Armand M, Pasquier B, André M, et al. 1999. Digestion and absorption of 2 fat emulsions with different droplet sizes in the human digestive tract. Am J Clin Nutr 70: 1096-1106.

Awada M, Meynier A, Soulage CO, et al. 2013. N-3 PUFA added to high-fat diets affect differently adiposity and inflammation when carried by phospholipids or triacylglycerols in mice. Nutr Metab 10.
Bakala N'Goma JC, Amara S, Dridi K, Jannin V, Carrière F. 2012. Understanding the lipid-digestion processes in the gi tract before designing lipid-based drug-delivery systems. Ther Deliv 3: 105-124.

Benzonana G, Desnuelle P. 1965. Kinetic study of the action of pancreatic lipase on emulsified triglycerides. Enzymology assay in heterogeneous medium. Biochim Biophys Acta 105: 121-136.

Bernoud-Hubac N, Hachem M, Lo Van A, Picq M, Lagarde M, 2017. Specific uptake of DHA by the brain from a structured phospholipid, AceDoPC ${ }^{\circledR}$. OCL, DOI: 10.1051/oc1/2016053.

Besnard P. 2016. Perception oro-sensorielle des lipides alimentaires et obésité. OCL 23: D308.

Boivin M, Lanspa SJ, Zinsmeister AR, Go VLW, Dimagno EP. 1990. Are diets associated with different rates of human interdigestive and postprandial pancreatic-enzyme secretion. Gastroenterology 99: 1763-1771.

Borel P, Armand M, Pasquier B, et al. 1994. Digestion and absorption of tube-feeding emulsions with different droplet sizes and compositions in the rat. J Parenter Enteral Nutr 18: 534-543.

Bunea R, El Farrah K, Deutsch L. 2004. Evaluation of the effects of neptune krill oil on the clinical course of hyperlipidemia. Altern Med Rev 9: 420-428.

Carey MC, Small DM, Bliss CM. 1983. Lipid digestion and absorption. Annu Rev Physiol 45: 651-677.

Carrière F, Barrowman JA, Verger R, Laugier R. 1993. Secretion and contribution to lipolysis of gastric and pancreatic lipases during a test meal in humans. Gastroenterology 105: 876-888.

Carrière F, Rogalska E, Cudrey C, Ferrato F, Laugier R, Verger R. 1997. In vivo and in vitro studies on the stereoselective hydrolysis of tri- and diglycerides by gastric and pancreatic lipases. Bioorg Med Chem 5: 429-435.

Carrière F, Renou C, Lopez V, et al. 2000. The specific activities of human digestive lipases measured from the in vivo and in vitro lipolysis of test meals. Gastroenterology 119: 949-960.

Carrière $\mathrm{F}$, Renou $\mathrm{C}$, Ransac $\mathrm{S}$, et al. 2001. Inhibition of gastrointestinal lipolysis by orlistat during digestion of test meals in healthy volunteers. Am J Physiol Gastrointest Liver Physiol 281: G16-G28.

Carrière F, Grandval P, Gregory PC, et al. 2005. Does the pancreas really produce much more lipase than required for fat digestion? $J$ Pancreas 6: 206-215.

Christensen MS, Hoy CE. 1996. Effects of dietary triacylglycerol structure on triacylglycerols of resultant chylomicrons from fish oil- and seal oil-fed rats. Lipids 31: 341-344.

Christensen MS, Hoy CE, Redgrave TG. 1994. Lymphatic absorption of n-3 polyunsaturated fatty acids from marine oils with different intramolecular fatty acid distributions. Biochim Biophys Acta 1215: 198-204.

Cook CM, Larsen TS, Derrig LD, Kelly KM, Tande KS. 2016. Wax ester rich oil from the marine crustacean, Calanus finmarchicus, is a bioavailable source of EPA and DHA for human consumption. Lipids 51: 1137-1144.

Corstens MN, Berton-Carabin CC, De Vries R, Troost FJ, Masclee AAM, Schroën K. 2017. Food-grade micro-encapsulation systems that may induce satiety via delayed lipolysis: a review. Crit Rev Food Sci Nutr. 57: 2218-2244. DOI:10.1080/ 10408398.2015.105763400-00.

Couedelo L, Vaysse C, Vaique E, et al. 2012. The fraction of alphalinolenic acid present in the sn-2 position of structured triacylglycerols decreases in lymph chylomicrons and plasma triacylglycerols during the course of lipid absorption in rats. J Nutr 142: 70-75.

Couedelo L, Amara S, Lecomte M, et al. 2015. Impact of various emulsifiers on ALA bioavailability and chylomicron synthesis through changes in gastrointestinal lipolysis. Food Funct 6: 1726-1736. DOI: $10.1039 / \mathrm{c} 5$ fo00070j. 
Daher CF, Baroody GM, Howland RJ. 2003. Effect of a surfactant, Tween 80, on the formation and secretion of chylomicrons in the rat. Food Chem Toxicol 41: 575-582.

Favé G, Coste TC, Armand M. 2004. Physicochemical properties of lipids: new strategies to manage fatty acid bioavailability. Cell Mol Biol 50: 815-831.

Favé G, Leveque C, Peyrot J, Pieroni G, Coste TC, Armand M. 2007. Modulation of gastric lipolysis by the phospholipid specie: link to specific lipase-phospholipid interaction at the lipid/water interface? FASEB J 21: A1010.

Feron G, Poette J. 2013. In-mouth mechanism leading to the perception of fat in humans: From detection to preferences. The particular role of saliva. OCL 20: 102-107.

Feron G, Salles C. 2013. Rôle de la sphère orale. In: Fardet A, Souchon I, Dupont D, eds. Structure des aliments et effets nutritionnels. Paris: QUAE, pp. 35-55.

Foltz M, Maljaars J, Schuring EAH, et al. 2009. Intragastric layering of lipids delays lipid absorption and increases plasma CCK but has minor effects on gastric emptying and appetite. Am J Physiol Gastrointest Liver Physiol 296: G982-G991.

Freeman CP. 1969. Properties of fatty acids in dispersions of emulsified lipid and bile salt and the significance of these properties in fat absorption in the pig and the sheep. Br J Nutr 23: 249-263.

Garaiova I, Gushina IA, Plummer SF, Tang J, Wang D, Plummer NT. 2007. A randomised cross-over trial in healthy adults indicating improved absorption of omega-3 fatty acids by pre-emulsification. Nutr $J 6$.

Gargouri Y, Pieroni G, Riviere C, et al. 1986a. Importance of human gastric lipase for intestinal lipolysis - an in vitro study. Biochim Biophys Acta 879: 419-423.

Gargouri Y, Pieroni G, Riviere C, et al. 1986b. Kinetic assay of human gastric lipase on short-chain and long-chain triacylglycerol emulsions. Gastroenterology 91: 919-925.

Genot C, Guillet S, Métro B. 1989. Rheological properties of gelatin gels filled with phospholipid vesicles. Dynamic and uniaxial compresion measurements. Progr Colloid Polym Sci 79: 18-23.

Genot C, Eymard S, Viau M. 2004. Comment protéger les acides gras poly-insaturés à longues chaînes oméga 3 (AGPI - LC w3) vis-àvis de l'oxydation? OCL 11(2): 133-141.

Genot C, Berton C, Ropers MH. 2013a. The role of the interfacial layer and emulsifying proteins in the oxidation in oil-in water emulsions. In: Logan A, Nienaber U, Pan X, eds. Lipid oxidation: challenges in food systems. AOCS Press, pp. 177-210.

Genot C, Kabri TH, Meynier A. 2013b. 5-stabilisation of omega-3 oils and enriched foods using emulsifiers. In: Jacobsen C, Nielsen S, Frisenfeldt Horn A, Moltke Sorensen AD, eds. Food enrichment with omega-3 fatty acids. Cambridge: Woolhead Publishing Limited, pp. 150-193.

Genot C, Meynier A, Bernoud-Hubac N, Michalski MC. 2016. Bioavailability of lipids in fish and fish oils. In: Raatz SK, Bibus DM, eds. Fish and fish oil in health and disease prevention 1st ed. Academic Press, London, pp. 61-74.

Hamilton JA. 2007. New insights into the roles of proteins and lipids in membrane transport of fatty acids. Prostaglandins Leukot Essent Fatty Acids 77: 355-361.

Hamosh M. 1990. Lingual and gastric lipases: their role in fat digestion. Boca Raton, FL: CRC Press, pp. 1-239.

Hamosh M, Burns WA. 1977. Lipolytic-activity of human lingual glands (ebner). Lab Invest 37: 603-608.

Hamosh M, Bitman J, Liao TH, et al. 1989. Gastric lipolysis and fat-absorption in preterm infants - effect of medium-chain triglyceride or long-chain triglyceride-containing formulas. Pediatrics 83: 86-92.
Hofmann AF. 1963. The function of bile salts in fat absorption. The solvent properties of dilute micellar solutions of conjugated bile salts. Biochem $J$ 89: 57-68.

Hussein MO, Hoad CL, Wright J, et al. 2015. Fat emulsion intragastric stability and droplet size modulate gastrointestinal responses and subsequent food intake in young adults. J Nutr 145 : $1170-1177$.

Iqbal J, Hussain MM. 2009. Intestinal lipid absorption. Am J Physiol Endocrinol Metab 296: E1183-E1194.

Iverson SJ, Kirk CL, Hamosh M, Newsome J. 1991. Milk lipid digestion in the neonatal dog: the combined actions of gastric and bile salt stimulated lipases. Biochim Biophys Acta 1083: 109-119.

Joyce P, Whitby CP, Prestidge CA. 2016. Nanostructuring biomaterials with specific activities towards digestive enzymes for controlled gastrointestinal absorption of lipophilic bioactive molecules. Adv Colloid Interface Sci 237: 52-75.

Kalantzi L, Goumas K, Kalioras V, Abrahamsson B, Dressman JB, Reppas C. 2006. Characterization of the human upper gastrointestinal contents under conditions simulating bioavailability/ bioequivalence studies. Pharm Res 23: 165-176.

Kargar M, Spyropoulos F, Norton IT. 2011. The effect of interfacial microstructure on the lipid oxidation stability of oil-in-water emulsions. J Colloid Interface Sci 357: 527-533.

Karupaiah T, Sundram K. 2007. Effects of stereospecific positioning of fatty acids in triacylglycerol structures in native and randomized fats: A review of their nutritional implications. Nutr Metab 4.

Keogh JB, Wooster TJ, Golding M, Day L, Otto B, Clifton PM. 2011. Slowly and rapidly digested fat emulsions are equally satiating but their triglycerides are differently absorbed and metabolized in humans. J Nutr 141: 809-815.

Lagarde M, Bernoud-Hubac N. 2012. Relevance of DHA-containing lysophospholipids. Eur J Lipid Sci Technol 114: 112-113.

Lagarde M, Bernoud N, Brossard N, et al. 2001. Lysophosphatidylcholine as a preferred carrier form of docosahexaenoic acid to the brain. J Mol Neurosci 16: 201-204.

Lai HC, Ney DM. 1998. Gastric digestion modifies absorption of butterfat into lymph chylomicrons in rats. J Nutr 128: 2403-2410.

Laugerette F, Passilly-Degrace P, Patris B, et al. 2005. CD36 involvement in orosensory detection of dietary lipids, spontaneous fat preference, and digestive secretions. J Clin Invest 115 : $3177-3184$

Linderborg KM, Kallio HPT. 2005. Triacylglycerol fatty acid positional distribution and postprandial lipid metabolism. Food Rev Int 21: 331-355.

Livney YD. 2015. Nanostructured delivery systems in food: Latest developments and potential future directions. Curr Opin Food Sci 3: $125-135$.

Lo CM, Tso P. 2009. Physicochemical basis of the digestion and absorption of triacylglycerol. In: McClements DJ, Decker EA, eds. Designing functional foods. Measuring and controlling food structure breakdown and nutrient absorption. Oxford: Woodhead Publishing, pp. 94-126.

Lopez C. 2011. Milk fat globules enveloped by their biological membrane: unique colloidal assemblies with a specific composition and structure. Curr Opin Colloid Interface Sci 16: 391-404.

Lopez C, Madec MN, Jimenez-Flores R. 2010. Presence of lipid rafts in the bovine milk fat globule membrane revealed by the lateral segregation of phospholipids and heterogeneous distribution of glycoproteins. Food Chem 120: 22-33.

Mao LK, Miao S. 2015. Structuring food emulsions to improve nutrient delivery during digestion. Food Eng Rev 7: 439-451. 
Marciani L, Wickham M, Singh G, et al. 2007. Enhancement of intragastric acid stability of a fat emulsion meal delays gastric emptying and increases cholocystokinin release and gallbladder contraction. Am J Physiol Gastrointest Liver Physiol 296: G982-G991.

Marciani L, Faulks R, Wickham MSJ, et al. 2009. Effect of intragastric acid stability of fat emulsions on gastric emptying, plasma lipid profile and postprandial satiety. Br J Nutr 101: 919-928.

Marefati A, Rayner M, Timgren A, Dejmek P, Sjoo M. 2013. Freezing and freeze-drying of pickering emulsions stabilized by starch granules. Colloids Surf A: Physicochem Eng Aspects 436: 512-520.

Masuda D, Hirano K, Oku H, et al. 2009. Chylomicron remnants are increased in the postprandial state in CD36 deficiency. J Lipid Res 50: 999-1011.

Mattes RD. 2011. Oral fatty acid signaling and intestinal lipid processing: support and supposition. Physiol Behav 105: 27-35.

McClements DJ. 2015. Reduced-fat foods: the complex science of developing diet-based strategies for tackling overweight and obesity. Adv Nutr 6: 338S-352S.

Mekki N, Charbonnier M, Borel P, et al. 2002. Butter differs from olive oil and sunflower oil in its effects on postprandial lipemia and triacylglycerol-rich lipoproteins after single mixed meals in healthy young men. $J$ Nutr 132: 3642-3649.

Meynier A, Michalski MC, Marze S, Kenmogne-Domguia HB, Awada M, Genot C. 2013. Devenir digestif et effets métaboliques des matrices formulées à base de lipides. In: Fardet A, Souchon I, Dupont D, eds. Structure des aliments et effets nutritionnels. Paris: QUAE, pp. 215-240.

Michalski MC, Genot C, Gayet C, et al. 2013. Multiscale structures of lipids in foods as parameters affecting fatty acid bioavailability and lipid metabolism. Prog Lipid Res 52: 354-373.

Moreau H, Laugier R, Gargouri Y, Ferrato F, Verger R. 1988. Human preduodenal lipase is entirely of gastric fundic origin. Gastroenterology 95: 1221-1226.

$\mathrm{Mu} \mathrm{H}$, Porsgaard T. 2005. The metabolism of structured triacylglycerols. Prog Lipid Res 44: 430-448.

Norton JE, Gonzalez Espinosa Y, Watson RL, Spyropoulos F, Norton IT. 2015. Functional food microstructures for macronutrient release and delivery. Food Funct 6: 663-678.

Poette J, Mekoué J, Neyraud E, et al. 2014. Fat sensitivity in humans: Oleic acid detection threshold is linked to saliva composition and oral volume. Flav Fragr J 29: 39-49.
Raynal-Ljutovac K, Bouvier J, Gayet C, et al. 2011. Organisation structurale et moléculaire des lipides dans les aliments : Impacts possibles sur leur digestion et leur assimilation par l'homme. $O C L$ 18: 324-351.

Rayner M, Marku D, Eriksson M, Sjoo M, Dejmek P, Wahlgren M. 2014. Biomass-based particles for the formulation of pickering type emulsions in food and topical applications. Colloids Surf A: Physicochem Eng Aspects 458: 48-62.

Roman C, Carriere F, Villeneuve P, et al. 2007. Quantitative and qualitative study of gastric lipolysis in premature infants: do MCT-enriched infant formulas improve fat digestion? Pediatr Res 61: 83-88.

Singh H, Ye A, Horne D. 2009. Structuring food emulsions in the gastrointestinal tract to modify lipid digestion. Prog Lipid Res 48: 92-100.

Singh H, Ye AQ, Ferrua MJ. 2015. Aspects of food structures in the digestive tract. Curr Opin Food Sci 3: 85-93.

Sugasini D, Devaraj VC, Ramesh M, Lokesh BR. 2014. Lymphatic transport of $\alpha$-linolenic acid and its conversion to long chain n-3 fatty acids in rats fed microemulsions of linseed oil. Lipids 49: 225-233.

Tressou J, Pasteau S, Dartinet SD, Simon N. 2016. Données récentes sur les apports en acides gras des français. OCL 23: D303.

Velikov KP, Pelan E. 2008. Colloidal delivery systems for micronutrients and nutraceuticals. Soft Matter 4: 1964-1980.

Vors C, Pineau G, Gabert L, et al. 2013. Modulating absorption and postprandial handling of dietary fatty acids by structuring fat in the meal: a randomized crossover clinical trial. Am J Clin Nutr 97: 23-36.

Yao MF, Xiao H, McClements DJ. 2014. Delivery of lipophilic bioactives: assembly, disassembly, and reassembly of lipid nanoparticles. In: Doyle MP, Klaenhammer TR, eds. Annual review of food science and technology, Vol. 5. Palo Alto: Annual Reviews, pp. 53-81.

Yoshida H, Mawatari M, Ikeda I, Imaizumi K, Seto A, Tsuji H. 1999. Effect of dietary seal and fish oils on triacylglycerol metabolism in rats. J Nutr Sci Vitaminol (Tokyo) 45: 411-421.

Zhang ZP, Zhang RJ, Zou LQ, McClements DJ. 2016. Tailoring lipid digestion profiles using combined delivery systems: mixtures of nanoemulsions and filled hydrogel beads. RSC $A d v$ 6: 65631-65637.

Cite this article as: Meynier A, Genot C. 2017. Molecular and structural organization of lipids in foods: their fate during digestion and impact in nutrition. $O C L$ 24(2): D202. 